\title{
Predictors of falls and hospitalization outcomes in elderly patients admitted to an acute geriatric unit
}

\author{
Laura Corsinovi *, Mario Bo, Nicoletta Ricauda Aimonino, Renata Marinello, Federico Gariglio, \\ Cristina Marchetto, Laura Gastaldi, Laura Fissore, Mauro Zanocchi, Mario Molaschi
}

Section of Geriatrics, Department of Medical and Surgical Disciplines, Ospedale San Giovanni Battista-Molinette, Corso Bramante 88, I-10126 Torino, Italy

\section{A R T I C L E I N F O}

\section{Article history:}

Received 20 February 2008

Received in revised form 9 June 2008

Accepted 11 June 2008

Available online 31 July 2008

\section{Keywords:}

Falls in elderly

Hospitalization of fallen elderly

Length of stay (LOS)

\begin{abstract}
A B S T R A C T
We aimed to identify fall incidence, predictors and characteristics and to investigate hospitalization outcomes for elderly inpatients. In 340 men and 280 women consecutively admitted to a Acute Geriatric Ward of a University Hospital the following variables were evaluated: demographics, clinical history, main disease responsible for hospitalization, comorbidity (cumulative illness rating scale: CIRS 1 and 2) gait and balance deficit (Tinetti's scales), cognition/function (short portable mental status questionnaire: SPMSQ); activities of daily living: ADL; instrumental activities of daily living: IADL; delirium (confusion assessment method: CAM), drugs administered during hospitalization. Overall 80 falls occurred in 70 patients. The incidence rate of falls was of 6.0 per 1000 patient-days with 2.0 falls per bed/year. Age (relative risk $=\mathrm{RR}=1.050 ; 95 \%$ confidence interval $=\mathrm{CI}=1.013-1.087)$, delirium $(\mathrm{RR}=3.577 ; 95 \% \mathrm{CI}$ 1.096-11.672), diabetes $(R R=5.913 ; 95 \%$ CI 1.693-20.644), balance deficit $(R R=0.914 ; 95 \%$ CI $0.861-$ $0.970)$ and polypharmacy $(R R=1.226$; $95 \%$ CI $1.122-1.340)$ were independently predictive of falling. Fallers had a prolonged length of stay (LOS) ( $35.5 \pm 47.8$ days vs. $23.2 \pm 27.2 ; p=0.01)$ and more frequent nursing home placements $(12.9 \%$ vs.5.6\%; $p<0.005)$. The knowledge of falling predictors might help in planning specific preventive strategies to improve the patients' global health status and to reduce the costs of medical care.
\end{abstract}

(c) 2008 Published by Elsevier Ireland Ltd.

\section{Introduction}

Falls are a very common type of inpatient accident (ANARI, 2004; Nakai et al., 2006) and with their physical and psychological consequences might compromise an already impaired functional status or cause severe morbidity and mortality in old people (Rubenstein and Josephson, 2006). The incidence of falls rises steadily from middle-aged people and peaks in those who are over 80 years (Rubenstein and Josephson, 2002). In hospitalized people, fall rates might vary from 3 to 13 per 1000 patient-days, depending on department type and patient population, as reported in a recent review (Oliver et al., 2007).

Most falls result from a complex interplay of predisposing and precipitating factors in people's environment and in individual demographic and clinical characteristics. Hospitalization itself may be an important risk factor in falls, representing a deep change in elderly patients' life habits. In addition, preventing hospital falls

\footnotetext{
* Corresponding author. Tel.: +39011633 6743; fax: +39 0116961045 . E-mail address: laura.corsinovi@unito.it (L. Corsinovi).
}

requires knowledge of falls and injury circumstances in different settings (Krauss et al., 2007).

Considering that an early identification of hospitalized patients at risk of falling might help to prevent this issue, the aim of our study was to evaluate fall incidence, predictors and characteristics and to investigate hospitalization outcomes for elderly inpatients admitted to a Geriatric Acute Care Ward of a University Hospital.

\section{Materials and methods}

Approval was obtained by the Local Ethic Committee. This longitudinal observational study recruited 620 patients (mean age $79.3 \pm 8.9$ years) consecutively admitted to the Geriatric Acute Care Unit of San Giovanni Battista Hospital in Turin, between August 1st 2006 and December 31st 2007.

Upon hospital admission, using predefined forms, we gathered the following variables for each patient: demographic data (age, sex), the main disease causing hospital admission, the associated pathologies, according to the International Classification of Diseases, Ninth Revision Clinical Modification, (ICD-9-CM) and the concomitant diseases through the CIRS with both the index of severity (CIRS 1) and the index of comorbidity (CIRS 2) (Linn et al., 
1968). Furthermore, we evaluated the body mass index (BMI), the presence of visual impairment, incontinence, sleep-wake disturbance and orthostatic hypotension (defined as a $20 \mathrm{mmHg}$ fall in systolic blood pressure on assuming an upright posture from a supine position).

We also investigated the gait and balance disturbances through Tinetti's performance-oriented assessment of gait and his performance-oriented assessment of balance (Tinetti, 1986), respectively. These tests are scored on the patient's ability to perform specific tasks. The maximum scores for the gait components and the balance components are 12 and 16 , respectively. We also noted the number of prior falls in the last 6 months, the presence of mechanical restraints (bed rails or soft restraining vests) and the need for ambulation assistive devices.

Functional status was assessed through the ADL (Katz et al., 1963), and the IADL (Lawton and Brody, 1969). Patients with ADL score $\geq 1$ or IADL $\leq 5$ were considered functionally dependent. We evaluated the cognitive status through the SPMSQ (Pfeiffer, 1975) and the presence of delirium symptoms through the CAM (Inouye et al., 1990). Patients with SPMSQ score ranging from 3 to 4,5 to 7 and 8 to 10 were considered suffering from mild, moderate and severe intellectual impairments, respectively. The CAM is an assessment instrument that screens for clinical features of delirium and correlates to DSM IV criteria. The short version includes only those four features that were found to have the greatest ability to distinguish delirium from other types of cognitive impairments.

We also assessed the outcomes of hospitalization (LOS, death, nursing home placement, discharge to home) and the pharmacological therapies administered to the patients during hospitalization.

In this study a "fall" was defined as any event registered as a fall in the medical or nursing records (Tutuarima et al., 1997); we only considered the occurrence of complete falls (not avoided nor assisted falls). For each fall we noted time, setting, circumstances, number of days between the hospital admission and the fall and its clinical consequences (wounds, fractures, subdural hematoma).

\subsection{Statistical analysis}

The statistical analysis was performed using SPSS, version 11.5 for Windows. In the univariate analysis we used $\chi^{2}$-test and Student's $t$-test to evaluate dichotomous and continuous variables, respectively. Significant variables were then introduced into the multivariate analysis by means of logistic regression model to identify the main predictors of falling during hospitalization.

\section{Results}

During the study period, 80 falls occurred in 70 hospitalized patients (11.3\% of the 620 subjects enrolled). Among these 70 fallers, $9(12.8 \%)$ fell more than once. The total number of patientdays was 13,356 for 28 beds with an incidence rate of falls of 6.0 falls per 1000 patient-days and 2.0 falls per bed/year.

Fallers were older than non-fallers $(82.1 \pm 7.9$ years vs. $78.9 \pm 8.9$ years, $p<0.001)$. No difference in fall incidence was found between men (12.9\%) and women (10.0\%). Mortality rate was similar among fallers and non-fallers (11.4\% and $11.3 \%$, respectively). A prolonged LOS ( $35.5 \pm 47.8$ days vs. $23.2 \pm 27.2$ days; $p=0.01)$ and nursing home placements $(12.9 \%$ vs. $5.6 \%$; $p<0.005)$ were more frequent among fallers than non-fallers.

Table 1 shows the incidence and the characteristics of falls. Roughly half of falls (51.5\%) occurred within the first week of hospitalization and particularly within the first 3 days. The majority of events happened in the daytime and in the patients'
Table 1

Incidence and characteristics of falls

\begin{tabular}{|c|c|c|}
\hline & Number & $\%$ of fallen patients \\
\hline \multicolumn{3}{|c|}{ Time between hospitalization and 1st fall } \\
\hline$\leq 3$ days & 27 & 38.6 \\
\hline 4 days-1 week & 9 & 12.9 \\
\hline 1-2 weeks & 22 & 31.4 \\
\hline 2 weeks- 1 month & 7 & 10 \\
\hline$>1$ month & 5 & 7.1 \\
\hline \multicolumn{3}{|c|}{ Timing of fall (round the clock) } \\
\hline $24-6$ & 20 & 25 \\
\hline $6-13$ & 28 & 35 \\
\hline $13-20$ & 23 & 28.7 \\
\hline $20-24$ & 9 & 11.3 \\
\hline \multicolumn{3}{|l|}{ Location of fall } \\
\hline Patient's room & 59 & 73.7 \\
\hline Toilet/bathroom & 11 & 13.7 \\
\hline Corridor & 10 & 12.6 \\
\hline \multicolumn{3}{|l|}{ Circumstances of fall } \\
\hline During ambulation & 32 & 40 \\
\hline From the wheel-chair & 7 & 8.7 \\
\hline From the bed & 41 & 51.3 \\
\hline \multicolumn{3}{|c|}{ Clinical consequences of falling } \\
\hline None & 53 & 75.7 \\
\hline Lacerations & 9 & 12.8 \\
\hline Femur fracture & 2 & 2.9 \\
\hline Humer fracture & 2 & 2.9 \\
\hline Vertebral fracture & 1 & 1.4 \\
\hline Other fractures & 2 & 2.9 \\
\hline Subdural hematoma & 1 & 1.4 \\
\hline
\end{tabular}

room. Only $13.7 \%$ of falls occur in the bathroom and $12.6 \%$ in the corridors. 51\% of falls took place from the patients' bed.

A significantly greater number of patients who had resulted to be dependent in ADL fell performing basic activities of daily living, but we did not find any difference in incidence related to IADL and SPMSQ scores (Table 2). As summarized in Table 3 fallers scored significantly lower on Tinetti's scales for both balance and gait $(4.90 \pm 5.04$ and $5.04 \pm 4.57$ vs. $7.49 \pm 6.25$ and $6.99 \pm 5.42$, respectively; $p<0.01$ ). The need for assistive devices for ambulation was associated to superior incidence of falling (22\% vs. $10.4 \%$, $p<0.05$ ), whereas there was no statistically significant relationship with a prior history of falling, using wheel-chair and physical restraints.

Delirious symptoms, as defined in the CAM scale, were also associated with superior incidence of falls (27.3\% vs. $10.7 \%$ ). Moreover, patients affected by endocrino-metabolic and genitourinary diseases fell more than patients without these pathologies. ( $31.3 \%$ vs. $10.8 \%$ and $25 \%$ vs. $10.8 \%$, respectively). We did not find

Table 2

Relationship between functional and cognitive status and falls: $N(\%)$

\begin{tabular}{lclc}
\hline & Total & Fallers & $p$ \\
\hline $\begin{array}{l}\text { IADL } \\
\text { Independent }\end{array}$ & 267 & $22(8.2)$ & $\mathrm{ns}$ \\
$\quad \begin{array}{l}\text { Partially dependent } \\
\text { Dependent }\end{array}$ & 155 & $20(12.9)$ & $\mathrm{ns}$ \\
ADL & 198 & $28(14.1)$ & $\mathrm{ns}$ \\
$\quad$ & & \\
Independent & & $22(7.7)$ & $<0.001$ \\
Dependent & 286 & $48(14.4)$ & $<0.001$ \\
SPMSQ (level of cognitive impairment) & & $\mathrm{ns}$ \\
$\quad$ None/slight & 430 & $47(10.9)$ & $\mathrm{ns}$ \\
$\quad \begin{array}{l}\text { Moderate } \\
\text { Severe }\end{array}$ & 83 & $13(15.7)$ & $\mathrm{ns}$ \\
\hline
\end{tabular}

Note: ns = not significant. 
Table 3

Relationship between Tinetti scale, ambulation, history of prior falls and falls: mean \pm S.D. or $N(\%)$

\begin{tabular}{|c|c|c|c|c|}
\hline & Total & Non-fallers & Fallers & $p$ \\
\hline \multicolumn{5}{|l|}{ Tinetti scale } \\
\hline Balance & $7.19 \pm 6.17$ & $7.49 \pm 6.25$ & $4.90 \pm 5.04$ & $<0.01$ \\
\hline Gait & $6.67 \pm 5.11$ & $6.99 \pm 5.42$ & $5.04 \pm 4.57$ & $<0.01$ \\
\hline \multicolumn{5}{|c|}{ Use of ambulation devices } \\
\hline No & 570 & $511(89.6)$ & $59(10.4)$ & $<0.05$ \\
\hline Yes & 50 & $39(78.0)$ & $11(22.0)$ & $<0.05$ \\
\hline \multicolumn{5}{|l|}{ Use of bed-rise } \\
\hline No & 572 & $506(88.5)$ & $66(11.5)$ & ns \\
\hline Yes & 48 & $44(91.7)$ & $4(8.3)$ & ns \\
\hline \multicolumn{5}{|l|}{ Use of wheel-chair } \\
\hline No & 526 & $471(89.5)$ & $55(10.5)$ & ns \\
\hline Yes & 94 & $79(84)$ & $15(16)$ & ns \\
\hline \multicolumn{5}{|c|}{ No. of falls in the last 6 months before hospital admission } \\
\hline None & 460 & $411(89.3)$ & $49(10.7)$ & ns \\
\hline 1 fall & 106 & $95(89.6)$ & $11(10.4)$ & ns \\
\hline 2 or more falls & 54 & $44(81.5)$ & $10(18.5)$ & ns \\
\hline
\end{tabular}

Table 4

Variables independently predictive of falls according to a multivariate analysis by means of logistic regression model

\begin{tabular}{|c|c|c|c|c|c|}
\hline & $\beta$ & \pm S.E.M. & RR & CI $95 \%$ & $p$ \\
\hline Age & 0.048 & 0.018 & 1.050 & $1.013-1.087$ & $<0.01$ \\
\hline \multicolumn{6}{|c|}{ Balance impairment (Tinetti scale) } \\
\hline & -0.090 & 0.030 & 0.914 & $0.861-0.970$ & $<0.01$ \\
\hline Delirium & 1.274 & 0.603 & 3.577 & $1.096-11.672$ & $<0.05$ \\
\hline \multicolumn{6}{|c|}{ Endocrino-metabolic disease } \\
\hline & 1.777 & 0.638 & 5.913 & $1.693-20.644$ & $<0.01$ \\
\hline Polypharmacy & 0.204 & 0.045 & 1.226 & $1.122-1.340$ & $<0.001$ \\
\hline
\end{tabular}

any difference related to CIRS 1 and CIRS 2 scores, BMI, visual impairment, incontinence, sleep-wake disturbance and orthostatic hypotension.

Some therapies administered during hospitalization, such as benzodiazepines, antidepressants, narcotics, calcium channel antagonists, diuretics and non-steroidal anti-inflammatory drugs were significantly associated to a higher number of falls. Furthermore, we found a significantly larger number of administered drugs in faller $(5.63 \pm 2.50)$ than in non-fallers $(3.03 \pm 3.38)$.

Age, the performance-oriented assessment of balance by Tinetti score, the presence of delirium, endocrino-metabolic disease and polypharmacy proved to be independently associated with the falls, as showed in Table 4.

Falls did not cause serious injuries in most cases (75.7\%). The most frequent consequence was a wound. $2.9 \%$ of patients sustained a hip fracture and one patient suffered from subdural hematoma as a result of a head trauma.

\section{Discussion}

In our study 70 elderly inpatients (11.3\%) fell during hospitalization in an Acute Geriatric Ward and the incidence rate of fall was 6.0 falls per 1000 patient-days and 2.0 falls per bed/year. In medical literature data on this subject are not homogeneous because of the variety of patients and settings evaluated and the research designs. In previous study conducted in hospitalized patients the incidence of falls was 11.7 fall per 1000 patients-days in Swiss geriatric departments (Schwendimann et al., 2006), 8.9 in stroke elderly patients (Tutuarima et al., 1997), 6.12 in medicine and neurology services (Hitcho et al., 2004) and up to 15.9 in a geriatric unit for stroke rehabilitation (Nyberg and Gustafson, 1995). Frail and polypathological patients tend to fall more frequently.

We found that falls occur more often during the first week of hospitalization (51.3\%). This finding reinforces the hypothesis that hospitalization, leading to a loss of habitual benchmarks, itself represents an important and avoidable risk factor of falling. In elderly patients it is necessary to carefully evaluate the risk-tobenefit ratio before hospitalizing a subject, preferring a home based care setting (i.e., Home Hospitalization Services), whenever possible (Aimonino Ricauda et al., 2004, 2008).

The majority of events happened in the daytime and in the patients' room and roughly half of fall occurred when the patient was in bed, in keeping with previous study (Tutuarima et al., 1997). Only $13.7 \%$ of falls occur in the bathroom and $12.6 \%$ in the corridors. The patient functional status influenced the circumstances and the setting of falls. Patients without ambulation deficits fell more frequently in the room, in the bathroom and in the corridors, whereas subjects with impaired functional or cognitive status fell from the bed, attempting to climb over the bed rails or wandering aimlessly (Mahoney, 1998). Moreover, the patients who scored worse on the ADL scale fell more frequently performing activities of daily living, as reported in previous studies (Rubenstein and Josephson, 2006).

In our study balance instability, presence of delirium, endocrino-metabolic disease and polypharmacy proved to be independently associated with the falls (Evans et al., 2001; Oliver et al., 2004). The most frequent diagnosis reported in the endocrinometabolic group was diabetes.

A recent review on risk factor for falls in hospital setting highlighted as strong predictors of falling: gait instability, lower limbs weakness, urinary incontinence, frequency or need for assisted toileting, previous fall history, agitation, confusion, impaired judgment and prescription of "culprit" drugs, in particular centrally acting sedative hypnotics (Oliver et al., 2004). In addition advanced age, sensorial impairments, various pathologies (anemia, neoplasms, congestive heart failure, stroke etc.), environmental and staffing characteristics etc. have also been linked to higher risk of falls in inpatients (Evans et al., 2001).

We found that fallers were older than non-fallers. This is probably due to the high prevalence of age related physiologic changes and of clinical diseases that rises with advancing age (Rubenstein and Josephson, 2006) and not to the chronologic age per se (Evans et al., 2001). In our patients' sample there was no difference between men and women, even if in previous reports (Tromp et al., 1998) being female was a predictor of falling in several settings.

Patients affected by diabetes and genito-urinary diseases fell more than patients without these pathologies, whereas no difference was found on CIRS scale. The diabetic old patient may be prone to falls for several reasons such as hypoglycemic syncope, impaired ambulation for neuropathy, peripheral arterial diseases, foot problems, orthostatic hypotension, side effects of diabetes medications (Krauss et al., 2005). The increased rate of falls associated with genito-urinary diseases, even if in our study this relationship loose strength in multivariate analysis, is due to special toileting needs (such as urgency and frequency) (Evans et al., 2001; King, 2003).

Although fallers scored lower on both balance and gait Tinetti's scale, after multivariate analysis only balance instability remained as an independent predictor of falling. Factors directly or indirectly related to mobility were identified as being associated with a greater risk of falling in several researches (Evans et al., 2001; King, 2003; Oliver et al., 2004; Vassallo et al., 2004). Delirious symptoms, as defined in the CAM scale, were also associated with superior 
incidence of falls. Altered mental status namely confusion, agitation or cognitive impairment are commonly described in patients at high risk of falling (Oliver et al., 2004; Krauss et al., 2005).

We found that certain drugs (such as benzodiazepines, antidepressants, narcotics, calcium channel antagonists, diuretics and non-steroidal anti-inflammatory drugs) and the presence of polypharmacy were significantly associated to a higher number of falls and that polypharmacy is an independent predictor of falling. While previous data are contradictory, polypharmacy (and especially taking more psychoactive drugs) has commonly been assumed to lead to a greater risk of falls (Cumming, 1998; Leipzig et al., 1999a,b; Evans et al., 2001; Landi et al., 2005). As a consequence, regular reviews of patients' medications, minimizing the psychotropic drugs unless really necessary, may be an appropriate and costless fall prevention strategy.

Similarly to previous investigations fallers presented a prolonged LOS and a greater prevalence of nursing home placement after hospital discharge, with a worsened quality of life for the patients and an increased health care cost burden (Vassallo et al., 2002).

Some limitations of this study should be discussed. The sample of population investigated consisted of older patients admitted to an acute geriatric department of a university-teaching hospital; therefore our findings should not be generalized to patients hospitalized in other institutions. In addition, the study was not designed as a randomized controlled trial but is a longitudinal observational study.

\section{Conclusion}

Falls in hospitalized elderly patients occur as a result of multiple factors, knowledge of which could help in planning adequate preventive strategies. In our study advancing age, balance deficit, acute cognitive impairment, diabetes and polypharmacy were significantly and independently associated to falls. Programs for preventing hospital falls should target patients with these risk factors using scheduled mobilization and toileting, providing exercise and physical therapy interventions and minimizing the use of medications related to falling. Since hospitalization itself may represent a risk of falling, a careful evaluation of risk/benefit ratio is needed before deciding to hospitalize elderly patients, preferring a home based care setting (i.e., Home Hospitalization Services), whenever possible. Appropriate measures, as individualized and as well-timed as possible, that reduce the risk of falling will have a remarkably good influence on patients' global health status and on the overall cost of medical care.

\section{Conflict of interest}

The authors have no conflicts of interest to declare and certify that no founding has been received for the conduct of this study and/or preparation of this manuscript.

\section{References}

Aimonino Ricauda, N.A., Bo, M., Molaschi, M., Massaia, M., Salerno, D., Amati, D., Tibaldi, V., Fabris, F., 2004. Home hospitalization service for acute uncomplicated first ischemic stroke in elderly patients: a randomized trial. J. Am. Geriatr Soc. 52, 278-283.

Aimonino Ricauda, N., Tibaldi, V., Leff, B., Scarafiotti, C., Marinello, R., Zanocchi, M., Molaschi, M., 2008. Substitutive "Hospital at Home" versus inpatient care for elderly patients with exacerbations of chronic obstructive pulmonary disease: a prospective randomized, controlled trial. J. Am. Geriatr. Soc. 56, 493-500.

ANARI (Australian National Ageing and Research Institute), 2004. An Analysis of Research on Preventing Falls and Falls Injury in Older People: Community, Residential and Hospital Settings. Australian Government Department of Health and Ageing, Canberra.

Cumming, R.G., 1998. Epidemiology of medication-related falls and fractures in the elderly. Drugs Aging 12, 43-53.

Evans, D., Hodgkinson, B., Lambert, L., Wood, J., 2001. Falls risk factors in the hospital setting: a systematic review. Int. J. Nurs. Pract. 7, 38-45.

Hitcho, E.B., Krauss, M.J., Birge, S., Claiborne Dunagan, W., Fischer, I., Johnson, S., Nast, P.A., Costantinou, E., Fraser, V.J., 2004. Characteristics and circum-stances of falls in a hospital setting: a prospective analysis. J. Gen. Intern. Med. 19, 732739.

Inouye, S.K., Van Dyck, C.H., Alessi, C.A., Balkin, S., Siegal, A.P., Horwitz, R.I., 1990. Clarifying confusion: the confusion assessment method. A new method for detection of delirium. Ann. Intern. Med. 113, 941-948.

Katz, S., Ford, A.B., Moskowitz, R.W., Jackson, B.A., Jaffe, M.W., 1963. Studies of illness in the aged. The index of ADL: a standardized measure of biological and psychosocial function. J. Am. Med. Assoc. 185, 914-919.

King, M.B., 2003. Falls. In: Hazzard, W.R., Blass, J.P., Halter, J.B., Ouslander, J.G. Tinetti, M.E. (Eds.), Principles of Geriatric Medicine and Gerontology. fifth ed. McGraw Hill, New York, pp. 1517-1529.

Krauss, M.J., Evanoff, B., Hitcho, E., Ngugi, K.E., Dunagan, W.C., Fischer, I., Birge, S., Johnson, S., Costantinou, E., Fraser, V.J., 2005. A case-control study of patient, medication, and care-related risk factors for inpatient falls. J. Gen. Intern. Med. 20, 116-122.

Krauss, M.J., Nguyen, S.L., Dunagan, W.C., Birge, S., Costantinou, E., Johnson, S., Caleca, B., Fraser, V.J., 2007. Circumstances of patient falls and injuries in 9 hospitals in a Midwestern healthcare system. Infect. Control Hosp. Epidemiol. 28, 544-550.

Landi, F., Onder, G., Cesari, M., Barillaro, C., Russo, A., Bernabei, R., the Silver Network Home Care Study Group, 2005. Psychotropic medications and risk for falls among community-dwelling frail older people: an observational study. J. Gerontol. A, Biol. Sci. Med. Sci. 60, M622-M626.

Lawton, M.P., Brody, E.M., 1969. Assessment of older people: self-maintaining and instrumental activities of daily living. Gerontologist 9, 179-186.

Leipzig, R.M., Cumming, R.G., Tinetti, M.E., 1999a. Drugs and falls in older people: a systematic review and meta-analysis. I. Psychotropic drugs. J. Am. Geriatr. Soc. 47, 30-39.

Leipzig, R.M., Cumming, R.G., Tinetti, M.E., 1999b. Drugs and falls in older people: a systematic review and meta-analysis. II. Cardiac and analgesic drugs. J. Am. Geriatr. Soc. 47, 40-50.

Linn, B.S., Linn, M.W., Gurel, L., 1968. Cumulative illness rating scale. J. Am. Geriatr. Soc. $16,622-626$.

Mahoney, J.E., 1998. Immobility and falls. Clin. Geriatr. Med. 14, 699-726.

Nakai, A., Akeda, M., Kawabata, I., 2006. Incidence and risk factors for inpatient falls in an academic acute-care hospital. J. Nippon Med. Sch. 73, 265-270.

Nyberg, L., Gustafson, Y., 1995. Patient falls in stroke rehabilitation. A challenge to rehabilitation strategies. Stroke 26, 838-842.

Oliver, D., Daly, F., Martin, F.C., McMurdo, M.E., 2004. Risk factors and risk assessment tools for falls in hospital in-patients: a systematic review. Age Ageing 33 , $122-130$.

Oliver, D., Connelly, J.B., Victor, C.R., Shaw, F.E., Whitehead, A., Genc, Y., Vanoli, A., Martin, F.C., Gosney, M.A., 2007. Strategies to prevent falls and fractures in hospitals and care homes and effect of cognitive impairment: systematic review and meta-analyses. Br. Med. J. 334, 82-88.

Pfeiffer, E., 1975. A short portable mental status evaluation questionnaire for the assessment of organic brain deficit in elderly patients. J. Am. Geriatr. Soc. 23, 433-441.

Rubenstein, L.Z., Josephson, K.R., 2002. The epidemiology of falls and syncope. Clin. Geriatr. Med. 18, 141-158.

Rubenstein, L.Z., Josephson, K.R., 2006. Falls and their prevention in elderly people: what does the evidence show? Med. Clin. North Am. 90, 807-824.

Schwendimann, R., Bühler, H., De Geest, S., Milisen, K., 2006. Falls and consequent injuries in hospitalized patients: effects of an interdisciplinary falls prevention program. BMC Health Serv. Res. 6, 69-75.

Tinetti, M.E., 1986. Performance-oriented assessment of motility problems in the elderly patients. J. Am. Geriatr. Soc. 34, 119-126.

Tromp, A.M., Smit, J.H., Deeg, D.J., Bouter, L.M., Lips, P., 1998. Predictors for falls and fractures in the Longitudinal Aging Study Amsterdam. J. Bone Miner. Res. 13, 1932-1939.

Tutuarima, J.A., Van der Meulen, J.H., De Haan, R.J., Van Straten, A., Limburg, M., 1997. Risk factors for falls of hospitalized stroke patients. Stroke 28, 297-301. Vassallo, M., Sharma, J.C., Allen, S.C., 2002. Characteristics of single fallers and recurrent fallers among hospital in-patients. Gerontology 48, 147-150.

Vassallo, M., Vignaraja, R., Sharma, J.C., Briggs, R., Allen, S.C., 2004. Predictors for falls among hospital inpatients with impaired mobility. J. R. Soc. Med. 97, 266-269. 